\title{
Sensitivity and representativeness of a childhood injury surveillance system
}

\author{
Colin Macarthur, Ivan Barry Pless
}

\begin{abstract}
Objective-To determine the sensitivity and representativeness of the Canadian Hospitals Injury Reporting and Prevention Program (CHIRPP).

Setting-The study was conducted in the Ottawa-Carleton region of Ontario, Canada (June through August, 1992).

Methods-Surveillance system sensitivity was estimated by dividing the number of injured children attending the Children's Hospital of Eastern Ontario (the only CHIRPP center in Ottawa-Carleton) by the total number of emergency department attended childhood injuries in the region. CHIRPP representativeness was assessed by comparing the injuries missed by the system with those captured on social, demographic, and clinical factors. Results-Sensitivity was 65\% (1552/2386). Missed and captured injuries were similar on sex, day, time of presentation, injury intent, and delay before presentation. Children older than 14 years, however, were more likely to be missed by the system; adjusted odds ratio 3.52 (95\% confidence interval (CI) 2.87 to 4.32 ). Conversely, children admitted to hospital were less likely to be missed; adjusted odds ratio $0.43(95 \%$ CI 0.23 to 0.80$)$.

Conclusion-Given the systematic errors in capture, CHIRPP data should be used cautiously in studies of etiology.

(Injury Prevention 1999;5:214-216)
\end{abstract}

Keywords: population surveillance; evaluation

Departments of Community Health Sciences and Paediatrics, University of Calgary, Calgary, Alberta, Canada

C Macarthur

Epidemiology and Biostatistics, McGill University and Injury Prevention Program, Montreal Children's Hospital, Montreal I B Pless

Correspondence to: Dr Colin Macarthur Associate Professor, Department of Community Health Sciences, Health Sciences Center, 3330 Hospital Drive NW, Calgary, Alberta, Canada T2N 4N1

(e-mail:

colinmac@ucalgary.ca).
Surveillance - the systematic collection, analysis, interpretation, and dissemination of data-is a key activity in the efforts to reduce childhood injury mortality and morbidity. ${ }^{1-4}$ Such data may be used to document the burden of the injury problem, determine priorities, identify populations at risk, and evaluate control programs. ${ }^{5}$ For example, a commitment to injury surveillance in Sweden (along with educational and legislative activities) lead to a significant decline in the childhood injury mortality rate in that country. ${ }^{6}$ Surveillance is expensive, however, both in terms of personnel and cost. Therefore, evaluation of the quality of the data provided by surveillance systems is essential. ${ }^{7}$ Two important system attributes related to data quality are sensitivity and representativeness. Sensitivity is the proportion of all health events of interest captured by the system, whereas, representativeness quantifies the nature of cap- ture, that is, whether or not there are systematic errors in capture.

The Canadian Hospitals Injury Reporting and Prevention Program (CHIRPP) is an emergency department based injury surveillance system administered by the federal government. Surveillance was inaugurated in 1990, with initial participation by all 10 children's hospitals across Canada. ${ }^{8}$ A standardized data collection form (completed by both the parent and the attending physician) is used to gather information on the injury event. Demographic, injury sequence, and clinical data are collected, with completed forms sent to Ottawa for coding and entry into a national database. The objective of this study was to determine the sensitivity and representativeness of CHIRPP.

\section{Methods}

For the purpose of this study, the surveillance population of interest was injured children presenting to a hospital emergency department. At the time of the study, the Ottawa-Carleton region of Ontario, Canada was served by a single paediatric tertiary facility (the Children's Hospital of Eastern Ontario) and five general hospitals with emergency department facilities: Montfort Hospital, Civic Hospital, General Hospital, Queensway-Carleton Hospital, and Riverside Hospital. (The Children's Hospital of Eastern Ontario was the only participant in CHIRPP.) Using intercensal estimates, the 1992 Ottawa-Carleton population was 682000 persons, of whom $25 \%$ were children ( $0-18$ years).

Data on injured children presenting to emergency departments in the region were collected over 30 days. Because of limited resources, simple random sampling, using a random numbers table, was used to select 10 days each month for three consecutive months (June through August, 1992). Injured children were identified through review of the emergency department registration logs and the medical charts at each hospital. (Registration logs are computerized files that contain clinical and demographic information on each patient presenting to the emergency department. This information is extracted from the emergency medical record by clerical staff.)

The numerator for CHIRPP sensitivity was the number of injured children attending the Children's Hospital of Eastern Ontario (and thus eligible for capture by the surveillance system), whereas, the denominator was the total number of emergency department attended childhood injuries in the region. Injured children transferred from a general 
Table 1 Representativeness of the CHIRPP: Ottawa-Carleton region, Ontario, Canada, summer 1992

\begin{tabular}{|c|c|c|c|c|}
\hline Predictor variable & No & $\begin{array}{l}\text { Missed by } \\
\text { CHIRPP (\%) }\end{array}$ & $\begin{array}{l}\text { Odds ratio of } \\
\text { being missed } \\
\text { (unadjusted) }\end{array}$ & $\begin{array}{l}95 \% \\
\text { Confidence } \\
\text { interval }\end{array}$ \\
\hline \multicolumn{5}{|l|}{ Sex } \\
\hline Male & 1416 & 36 & 1.08 & \multirow{2}{*}{0.91 to 1.28} \\
\hline Female & 964 & 34 & 1.00 & \\
\hline \multicolumn{5}{|l|}{ Day } \\
\hline Weekend & 784 & 37 & 1.13 & \multirow{2}{*}{0.94 to 1.34} \\
\hline Weekday & 1601 & 34 & 1.00 & \\
\hline \multicolumn{5}{|l|}{ Time of presentation } \\
\hline Night (1701-0759) & 1212 & 33 & 0.85 & \multirow[t]{2}{*}{0.72 to 1.01} \\
\hline Day $(0800-1700)$ & 1165 & 37 & 1.00 & \\
\hline \multicolumn{5}{|l|}{ Injury intent } \\
\hline Unintentional & 2326 & 35 & 0.44 & \multirow[t]{2}{*}{0.14 to 1.46} \\
\hline Intentional & 11 & 55 & 1.00 & \\
\hline \multicolumn{5}{|l|}{ Nature of injury } \\
\hline Laceration/abrasion & 617 & 41 & 1.37 & 1.11 to 1.68 \\
\hline Sprain & 268 & 44 & 1.55 & 1.18 to 2.03 \\
\hline Fracture/dislocation & 455 & 24 & 0.60 & 0.47 to 0.78 \\
\hline Concussion & 24 & 17 & 0.39 & \multirow[t]{2}{*}{0.14 to 1.10} \\
\hline Other & 1011 & 34 & 1.00 & \\
\hline \multicolumn{5}{|l|}{ Disposition } \\
\hline Admitted & 76 & 17 & 0.37 & \multirow[t]{2}{*}{0.20 to 0.68} \\
\hline Treated and released & 2295 & 36 & 1.00 & \\
\hline \multicolumn{5}{|l|}{ Age (years) } \\
\hline$>14$ & 503 & 59 & 3.57 & \multirow[t]{3}{*}{2.91 to 4.38} \\
\hline$\leqslant 14$ & 1843 & 29 & 1.00 & \\
\hline Total & 2386 & 35 & & \\
\hline
\end{tabular}

hospital to the Children's Hospital of Eastern Ontario were included in the numerator.

The representativeness of CHIRPP data was assessed by comparing injured children presenting to general hospitals (and thus missed by the system) with injured children presenting to the Children's Hospital of Eastern Ontario. Demographic, social, and clinical information were collected on both groups of injuries (missed and captured), using the medical chart as the primary data source. Predictor variables included the child's age and sex, day and time of presentation, delay before presentation, nature of injury, injury intent, and disposition. The univariate relationship between each of these independent variables and being missed by CHIRPP (yes/no) was examined, with stepwise logistic regression analysis used to assess the relative importance of the predictor variables. ${ }^{9}$

Sample size calculation was based on an $\alpha$ error of 0.05 , power of 0.80 , a $10 \%$ prevalence of the predictor variable among captured injuries, and the ability to detect a 1.5-fold increased risk of being missed by CHIRPP. Based on an anticipated missed:captured ratio of 1:2, 648 missed injuries and 1296 captured injuries were required. ${ }^{10}$ Given a frequency of around 50 injuries per day presenting to the emergency department of the Children's Hospital of Eastern Ontario, missed and captured injuries were accrued over 30 randomly selected days during the three summer months.

\section{Results}

Over the 30 days, 2386 children in the OttawaCarleton region presented to an emergency department because of injury. Of these, 1552 (65\%) presented to the Children's Hospital of Eastern Ontario (including 18 transfers). The remaining 834 injured children sought treatment at a general hospital. Of the five general hospitals in the region, however, injured children presented to only three: the
Queensway-Carleton Hospital (631 children), the Civic Hospital (107 children), and the Montfort Hospital (96 children). This pattern of utilization of general hospitals is likely explained by the close proximity of the General Hospital and the Riverside Hospital to the Children's Hospital of Eastern Ontario; both general hospitals are within several hundred yards of the paediatric facility. CHIRPP sensitivity was, therefore, 65\% (1552/2386); 95\% confidence interval (CI) $63 \%$ to $67 \%$.

The representativeness study compared the 834 missed injuries (that is, children presenting to general hospitals) with the 1552 injuries captured by CHIRPP (that is, children presenting to the Children's Hospital of Eastern Ontario). Univariate analyses showed no differences between missed and captured injuries on sex, day, time of presentation, or injury intent (see table 1). The median delay before presentation to the emergency department was one hour for both missed and captured injuries.

Nature of injury was coded using the 26 categories on the CHIRPP form. Analysis by this variable showed that "minor" injuries, for example, lacerations, abrasions, and sprains, were more likely to be missed by CHIRPP (see table 1). In contrast, more "severe" injuries, for example, fractures, dislocations, and concussions were less likely to be missed. (For concussions, the association was not statistically significant, largely because this injury type was relatively rare.) Analysis by disposition confirmed this observation. In other words, injuries resulting in admission to hospital were more likely to be captured by CHIRPP (that is, attend the Children's Hospital of Eastern Ontario), compared with injuries treated and released from the emergency department. In summary, minor injuries were more likely to be treated at a general hospital, whereas, severe injuries were more likely to be managed at the tertiary children's hospital. Because of the correlation between disposition and nature of injury, only disposition was retained in the logistic regression analysis.

The median age of missed injuries was 12 years, compared with a median age of eight years for captured injuries. Further graphical analysis by risk deciles showed a clear binary relationship between age and capture. Because of this relationship, age was modeled as a binary variable $(>14$ years compared with $\leqslant 14$ years). As shown in table 1 , older children were more likely to be missed by CHIRPP, compared with younger children. Of note, examination of the distribution of missed and captured injuries by nature of injury and by age showed consistent results. In other words, the pattern whereby specific minor injuries (for example, lacerations, abrasions, and sprains) were more likely to be missed by CHIRPP, while severe injuries (for example, fractures, dislocations, and concussions) were less likely to be missed was consistent for the two age groups $(>14$ years and $\leqslant 14$ years).

The main effects logistic regression model included only disposition and age. The adjusted odds ratio of being missed by CHIRPP for admitted injuries (compared with those 
treated and released) was 0.43 (95\% CI 0.23 to 0.80 ), whereas, the adjusted odds ratio of being missed by CHIRPP for children older than 14 years (compared with children 14 years or younger) was 3.52 (95\% CI 2.87 to 4.32 ). There was no interaction between disposition and age.

\section{Discussion}

This study showed that $35 \%$ of injured children in the Ottawa-Carleton region attended a general hospital and, therefore, were missed by CHIRPP. Comparison of missed with captured injuries also showed systematic errors in capture by the surveillance system; older children were more likely to be missed, whereas, severely injured children (that is, those admitted to hospital) were less likely to be missed.

Sampling bias was considered unlikely, given that simple random sampling was used to select the days for review. Information bias was minimized by using a standardized data collection form and the same data source (the medical chart) for both groups of injuries. Logistic regression analysis was used to adjust for the effects of confounding variables.

Calculation of CHIRPP sensitivity was based on the assumption of complete capture of childhood injuries presenting to the Children's Hospital of Eastern Ontario. Previous research, however, has shown that capture at specific CHIRPP centers varies from $30 \%$ to $90 \%{ }^{11}$ Therefore, based on a capture rate of $30 \%$ at the Children's Hospital of Eastern Ontario, CHIRPP sensitivity would decline to $20 \%(466 / 2386) ; 95 \%$ CI $18 \%$ to $22 \%$. A capture rate of $90 \%$ would give a CHIRPP sensitivity of $59 \%(1397 / 2386) ; 95 \%$ CI $57 \%$ to $61 \%$.

Inappropriate inclusion of non-injuries in the CHIRPP database has been shown to be negligible, with system specificity estimated at $100 \%{ }^{11}$ Further, in our study, 129 children (5\%) lived outside the Ottawa-Carleton region, with the majority attending the Children's Hospital of Eastern Ontario. Exclusion of these children from the analyses, however, did not materially alter the results.

The study was conducted over three summer months. Therefore, the influence of season on CHIRPP sensitivity and representativeness could not be assessed. Further, given that the research was conducted in a single region, cautious generalization of the findings is warranted. At the time of the study, however, the 10 CHIRPP centers across Canada were considered relatively homogeneous; all were urban, teaching, tertiary care paediatric centers affiliated with a local medical school. Further, it could be argued that the systematic errors in CHIRPP capture (that is, related to age and injury severity) speak to a pattern of health care utilization by families that is generalizable to most urban centers and not unique to the Ottawa-Carleton region.

Children older than 14 years were more likely to attend a general hospital and, therefore, be missed by CHIRPP. Possible explanations may be that the Children's Hospital of Eastern Ontario is perceived by the population as providing care to young children (0-14 years), or that adolescents themselves prefer a general hospital. Children admitted to hospital because of an injury, however, were more likely to attend the Children's Hospital of Eastern Ontario, that is, be captured by the surveillance system. It is likely that both parents and physicians choose that severely injured children be managed in the regional tertiary paediatric facility. Another explanation, however, is that admission policies for injured children may differ between general hospitals and children's hospitals.

Evaluation of the quality of injury surveillance data is necessary if prevention activities based on the data are to be appropriate and effective. ${ }^{7}$ CHIRPP collects national data on childhood injuries and, therefore, represents an important resource for research and policy development. Sensitivity is low, however, with almost one third of all emergency department attended injuries missed by the surveillance system. Therefore, any estimation of the national burden of childhood injury presenting to emergency departments, based on CHIRPP data alone, would require adjustment upwards.

Furthermore, there are systematic errors in CHIRPP capture. For example, adolescents are systematically missed by the surveillance system. This error limits the use of CHIRPP data to determine priorities, identify populations at risk, and evaluate control programs for injuries that predominantly affect this age group. In such situations, supplementary data from general hospitals may be necessary. In summary, although CHIRPP data may be useful for the identification of emerging problems and for hypotheses generation, given the systematic errors in capture, these data should be used cautiously in studies of etiology.

At the time of the study Dr Macarthur was a National Health Research and Development Program (NHRDP) Doctoral Fellow. Professor Pless is supported by a National Health Fellow. Professor Pless is supported by a National Health
Scientist Award from the National Health Research and Scientist Award from the National Heam, Ottawa, Ontario.
Development Program,

1 Langley JD. The role of surveillance in reducing morbidity and mortality from injuries. Morb Mortal Wkly Rep 1992;41(suppl):181-90.

2 Graitcer PL. Development of state and local injury surveillance systems. Fournal of Safety Research 1987;18:191-8.

3 Vimpani G. Injury surveillance: a key to effective control of childhood injuries. Australian Paediatric fournal 1989;25. $10-13$.

4 Ing RT. Surveillance in injury prevention. Public Health Rep 1985;100:586-8.

5 Thacker SB, Berkelman RL. Public health surveillance in the United States. Epidemiol Rev 1988;10:164-90.

6 Bergman AB, Rivara FP. Sweden's experience in reducing childhood injuries. Pediatrics 1991;88:69-74.

7 Klaucke DN. Evaluating public health surveillance. In: Teutsch SM, Churchill RE, eds. Principles and practice of public health surveillance. New York: Oxford University Press, 1994: 158-74.

8 Macarthur C, Dougherty G, Pless IB. Reliability and validity of proxy respondent information about childhood injury: an assessment of an Canadian surveillance system. Am f Epidemiol 1997;145:834-41.

9 Hosmer DW, Lemeshow S. Applied logistic regression. 1st Ed. New York: John Wiley, 1989

10 Schlesselman JJ. Case-control studies: design, conduct, analysis. 1 st Ed. New York: Oxford University Press, 1982.

11 Macarthur C, Pless IB. Evaluation of the quality of an injury surveillance system. Am f Epidemiol 1999;149:586-92. 